\title{
Optimization of Hybrid Renewable Energy in Sarawak Remote Rural Area Using HOMER Software
}

\author{
Yanuar Z. Arief \\ Dept. of Electrical and Electronic Eng. \\ Faculty of Engineering \\ Universiti Malaysia Sarawak \\ (UNIMAS) \\ Kota Samarahan,, Sarawak, Malaysia \\ ayzulardiansyah@unimas.my
}

\author{
Nur Anisah Aziera Abdul Halim \\ Dept. of Electrical and Electronic Eng. \\ Faculty of Engineering \\ Universiti Malaysia Sarawak \\ (UNIMAS) \\ Kota Samarahan,, Sarawak, Malaysia \\ anisahaziera1996@gmail.com
}

\author{
Mohd Hafiez Izzwan Saad \\ Dept. of Electrical and Electronic Eng. \\ Faculty of Engineering \\ Universiti Malaysia Sarawak \\ (UNIMAS) \\ Kota Samarahan,, Sarawak, Malaysia \\ smhizzwan@unimas.my
}

\begin{abstract}
In past few years, there has been a huge concern about decentralized electricity supply in Sarawak, Malaysia. Renewable energy resources can be seen as an alternative energy to capture the remote rural electrification's problems. Installing and operating a renewable energy generation is not difficult but it requires cautious step as to make sure maximum use of energy can improve the electrification. Therefore, the aim of this paper is to critically analyze five types of optimized hybrid renewable energy systems in term of financial and power production using HOMER software. This paper approaches four renewable energy resources, namely solar, hydro, wind and biomass in three remote rural areas located in Limbang, Kapit and Sri Aman regions. Different combination of solar PV system, micro-hydro generator, wind turbine and biomass generator together with battery storage and converter were studied. The optimization between these different sizes of system was built based on energy demand satisfaction, system cost and carbon gas emission. Comparison between operational of behaviors hybrid renewable energy systems with stand-alone diesel generator only were also carried out to elucidate the effects on investment cost and environment. The results revealed that hybrid hydro with battery system is seen to be the cheapest system and has the best technical performance in all locations. Solar PV and biomass generator system were combined with hydro generator as a backup power. It is also found that hybrid renewable energy is more cost-effective and reduce of carbon emission compared to standalone diesel generator.
\end{abstract}

Keywords-HOMER, hybrid renewable energy resources, remote rural area, net present cost, initial cost, operating cost.

\section{INTRODUCTION}

Electricity energy has been one of backbones of supporting socio-economic development to a modernize country as growing financial in industries and development in the standards of living is the reason of rising in energy consumption. Fossil fuels energy such as coal and natural gas of conventional energy contribute to greenhouse impact and start to appreciate natural resources in order to help electrification in some inaccessible rural areas. Based on the current rising trend of fuel prices in the world market, Malaysia government perceived the potential of renewable energy as an alternative option to make sure the sustainability of energy resources [1].

Sarawak has a low electrification access in Malaysia which most of them are living in unreachable electric grid of rural areas. The statistic in 2013 has stated that the Malaysia's electricity access rate had reached to $96.86 \%$. The percentage contribution of electricity in Peninsular Malaysia, Sabah and Sarawak are 99.72\%, 92.92\% and $88.01 \%$, respectively [2]. In 2016, SEB has identified 4,316 villages that consist of 40,000 homes in rural area have not received 24-hour electricity yet [3]. The lack of electricity intensifies the poverty where the developing countries have high demand for electricity. However, the government state and villagers are expected to have positive social economic impacts in the future.

The renewable energy resources is an alternative energy to capture the remote rural electrification's problems since the off-grid hybrid renewable energy focusing in rural area is to reduce the poverty rate. The combination of two or more hybrid renewable energy eventually give advantages in supporting the shortcoming of electrical energy and give strength to unpredictable renewable energy resources [4]. However, a major problem with this kind of application is to find the optimum hybrid energy that can satisfy customers' demand with minimum cost. This problem can be overcome by doing a deep research on the potential of renewable energy system.

The main objective of this work is to simulate hybrid renewable energy sources which consist of PV system, micro-hydro, wind turbine, and biomass generator at Sarawak rural remote area. This work also compares the cost for hybrid renewable energy sources with stand-alone diesel generator of electricity source only.

\section{METHOD}

\section{A. HOMER software}

HOMER that stands for Hybrid Optimization of Multiple Electric Renewables is a software developed by the National Renewable Energy Laboratory (NREL), US to design and evaluate technically and financially the options for off-grid and on-grid power systems for remote, stand-alone and distributed generation applications. HOMER calculates the mathematical data and generates results of feasible configurations sorted by Net Present Cost (NPC) to compares various design configurations on the basis of operational and economic rates. The possible system configurations can evaluate from HOMER's optimization and sensitivity analysis. 